\title{
Government Support, Entrepreneurial Activity and Firm Growth
}

\author{
https://doi.org/10.21272/sec.3(3).5-12.2019
}

Halil Dincer Kaya, PhD

Professor of Finance, Department of Accounting and Finance, College of Business and Technology, Northeastern State University, USA

\begin{abstract}
This paper summarizes the arguments and counterarguments within the scientific discussion on the issue of state and local governments' support of small businesses in U.S. states. The main purpose of the research is to determine whether state or local government's support positively affects entrepreneurial activity, firm growth, and business owner's optimism in the United States. Systematization of the literary sources and approaches for solving the problem of the impact of government support on entrepreneurial activity, growth, and optimism indicates that neither the support of state governments nor the support of local governments has a significant impact on the entrepreneurial activity in that state. However, the results show that both the support of state governments and the support of local governments have a significant impact on firm performance and owner's outlook for the future. In the states where there is above-average state or local government support as perceived by the owners, small firms are more successful and at the same time owners are more optimistic for the future. The relevance of the decision of this scientific problem is that, when deciding to support small businesses, governments need to know how this will affect different areas including activity, growth, or owner's morale. Investigation of the topic of the impact of government support on entrepreneurial activity, growth, and optimism in the paper is carried out in the following logical sequence: First, each state is assigned into one of two groups based on their score on state government support. The states that have a score higher than the mean state were assigned into the "High-State Govt Support" group and the others were assigned into the "Low-State Govt Support" group. Then, the two groups were compared in terms of entrepreneurial activity, firm performance, and optimism. Then, the same procedure is followed for local government support. The states that have a score higher than the mean state were assigned into the "High-Local Govt Support" group and the others were assigned into the "Low-Local Govt Support" group. The two groups were compared in terms of entrepreneurial activity, firm performance, and optimism. Methodological tools of the research methods were nonparametric tests for the year 2013. 41 states were examined because of lack of sufficient data for the other states. The paper presents the results of an empirical analysis for small firms in these states, which showed that government support is important for firm growth and owner's optimism. The research empirically confirms and theoretically proves that more state or local government support positively affects firm growth and optimism. The results of the research can be useful for governments that consider supporting small businesses in their region/area.
\end{abstract}

Keywords: entrepreneur, entrepreneurship, government support, growth, optimism, small business.

JEL Classification: G38, L25, L26.

Cite as: Kaya, H.D. (2019). Government Support, Entrepreneurial Activity and Firm Growth. SocioEconomic Challenges, 3(2), 5-12. https://doi.org/10.21272/sec.3(3).5-12.2019.

(C) The Author, 2019. This article is published with open access at Sumy State University.

\section{Introduction}

In this study, we examine the impact of state and local governments' support of small businesses in each U.S. state on the entrepreneurial activity in that state. As a measure of government support, we use the small business owners' perception of government support. We also examine how their perception of government support affects their optimism and their expectation for their firm's performance.

We employ the 2013 joint survey by Kauffman Foundation and Thumptack.com. The survey's name is "United States Small Business Friendliness Survey". This survey asks small firm owners questions about how they feel regarding their federal and local government support. 
Besides these questions, the survey asks small business owners about how optimistic they are with respect to their business. What is their expectation for their firm's growth? Would they encourage others to start a business in their state?

The Thumptack.com survey used the survey responses to create an "Entrepreneurial Activity Score" for each state. This score shows how business-friendly a state is. In this study, we use this score to see if there is a relation between small business owners' perception on government support and the entrepreneurial activity in that state.

We are hoping to contribute to the literature by finding how small business owners' perception on government support affect their optimism. Future studies may focus on the regional impacts. Each U.S. region has distinct characteristics; for example, the environment in the West Coast is different from the Midwest. Future studies may look into the relationship between a region's characteristics and small business owners' optimism.

Section 1 discusses the previous research. Section 2 explains our dataset and our methodology. Section 3 shows the empirical results. Section 4 concludes.

\section{Literature Review}

While we are doing a state-level analysis, there are several studies that look at the impact of various factors including regulations on entrepreneurship at the individual entrepreneur level. Dreher and Gassebner (2013) show that the existence of a larger number of procedures required to start a business, as well as larger minimum capital requirements are detrimental to entrepreneurship. They also show that corruption facilitates firm entry in highly regulated economies. Acs et al. (2009) develop a model that predicts that entrepreneurial activities decrease under greater regulation, administrative burden and market intervention by government.

Acs and Szerb (2007) contend that middle-income countries should focus on improving technology availability, increasing human capital, and promoting enterprise development, while developed countries should focus on labor market reforms and deregulation of financial markets. Kreft and Sobel (2005) argue that secure property rights, low regulation, and low taxes are important determinants of entrepreneurial activity. Klapper et al. (2006) find that costly regulations hamper the creation of new firms.

Nyström (2008) shows that a smaller government sector, better legal structure and security of property rights, less regulation of credit, labor and business tend to increase entrepreneurial activity. Parker (2007) shows that legal structures shape organizational forms in entrepreneurship. Legal rules and institutions also carry public policy implications for entrepreneurship. Stephan and Uhlaner (2010) show that opportunity existence and the quality of formal institutions support entrepreneurship.

Ovaska and Sobel (2005) show that credit availability, contract enforcement, low government corruption, sound monetary policy, high foreign direct investment, and policies supporting economic freedom are the most important factors for entrepreneurial activity.

Van Stel et al. (2007) find that while the minimum capital requirement and labor market regulations are important, the administrative considerations of starting a business are unrelated to the formation rate of either nascent or young businesses. Valdez and Richardson (2013) suggest that differences in values, beliefs, and abilities may play a greater role than purely economic considerations of opportunity and transaction costs.

According to Wennekers and Thurik (1999), culture, institutional framework, technological, demographic and economic forces are important for the entrepreneurial environment. Welter (2004) examines the environment for women entrepreneurs in Germany and concludes that there is a need for business chambers, business support agencies and associations, to adapt their approach towards women entrepreneurs.

Some of the studies are country-specific. Aidis et al. (2007) compare Lithuania and Ukraine who are at different stages in the process of transformation. The authors argue that these two countries differ in terms of their different inheritances from their Soviet past as well as their pace of change during the transition period. They contend that besides the formal institutions, the informal institutions such as gendered norms and values also restrict women's activities and their access to resources.

Aidis et al. (2008) examine how institutions/networks in Russia influenced entrepreneurial development. They show that existing firms benefit more from Russia's business environment when compared to newcomers in terms of new business start-ups. 
Branstetter et al. (2014) argue that Portugal's reforms had positively affected firm creation and employment, but that this is mostly true for "marginal firms". Bergmann and Sternberg (2007) focus on Germany and show that policies without any regional focus can have substantial regional implications. The individual start-up propensity in regions with rising unemployment is different from that in regions with stable or decreasing unemployment.

According to Bock (2004) who examines Dutch farmwomen, rural development policies do not help women as they usually promote an approach to entrepreneurship most common among men. Bitzenis and Nito (2005) show that the most important obstacles faced by entrepreneurs in Albania include unfair competition, changes in taxation procedures, lack of financial resources and problems related to public order. Bureaucracy and corruption do not appear to represent significant barriers to entrepreneurship.

Ghani et al. (2014) find that local education levels and physical infrastructure quality play the most important roles in promoting entry in India. They also show that strict labor regulations discourage entrepreneurship. García-Posada and Mora-Sanguinetti (2015) examine entrepreneurship and enforcement institutions in Spain. They find that higher judicial efficacy increases the entry rate of firms, while it has no effect on the exit rate.

Nawaser et al. (2011) find that laws, regulations and motivational factors are the obstacles for entrepreneurship development in Iran. Manolova et al. (2008) find that entrepreneurs in Hungary and Latvia were worried about the availability of knowledge and skills to engage in entrepreneurship. In Hungary, entrepreneurs were also skeptical about societal attitudes toward entrepreneurship, whereas in Bulgaria the entrepreneurs were dissatisfied with the laws, regulations, and government policies promoting entrepreneurship.

There are several more recent papers on the topic. These papers focus on several subtopics including "social entrepreneurship", "financial constraints for entrepreneurs", "the problems for female entrepreneurs", "entrepreneurial ecosystem", and "government support policies". Especially "entrepreneurial ecosystem" is a recent, popular topic for researchers. Researchers in this area focus on factors that would support the "entrepreneurial ecosystem", and these factors include "government support".

Akhmetshin et al. (2018) argue that, "in many countries of the world there is a great interest in social entrepreneurship on the part of legislators and governments". According to the authors, in developed countries, the budgets are cut therefore governments want to attract private capital to support social entrepreneurship.

Block et al. (2018) examine the financial constraints for young innovative firms. They analyze the new players that have entered the entrepeneurial finance arena. They argue that some of these new players in entrepreneurial financing like debt venture funds, angel networks, and family offices have been ignored in research. They also argue that while new firms often use several financing instruments simultaneously, most of the research focuses on single financing instruments such as VC or bank financing.

Ghouse et al. (2019) examine the problems experienced by cottage based women entrepreneurs in Oman. The authors show that certain problems like access to specialized suppliers, access to government, and high cost of raw materials are seen more important for these entrepreneurs, while marketing issues are seen as less important.

Hechavarría and Ingram (2019) examine how entrepreneurial ecosystem affects the prevalence of male and female entrepreneurship. They show that supportive government policy, low barriers to entry, a normative culture that supports entrepreneurship, and minimal commercial and legal infrastructure makes female entrepreneurship more prevalent. The authors also show that male entrepreneurship is more prevalent when government policy is supportive but when government programs aimed towards business creation are weak. Spigel and Harrison (2018) also emphasize the importance of entrepreneurial ecosystems. They argue that "the types of resources available in an ecosystem and the ability of these resources to flow through social networks" is important for the success of the ecosystem.

Holtbrügge and Berning (2018) examine the relationship between the market entry strategies of Chinese multinational enterprises and their performance in Germany. The authors find that the advantages of different market entry strategies are amplified by home government support.

Hoque (2018) investigates the mediating role of government support policy on the relationship between entrepreneurial orientation and performance of Bangladeshi Small and Medium Enterprises. The author shows that government support policy has a significant impact as a moderating variable on this relationship. 
Saberi and Hamdan (2019) examines how government support in the Gulf CooperationCouncil countries play a moderating role in the relationship between entrepreneurship and economic growth. The author shows that governmental support has a significant moderating effect on the relationship between economic growth and entrepreneurship in these countries.

Songling et al. (2018) find that government financial and non-financial support have a significant influence on the performance and competitive position of Pakistani Small and Medium Size Enterprises. The authors also show that a sustainable competitive position partially mediates the relationship between firm performance and government support.

Teixeira et al. (2018) examine entrepreneurial intention in European countries. They show that, in this region, there are several key determinants of entrepreneurial intention. The first determinant is the "perceived capacity" by the individual. The second determinant is the "entrepreneurial intention" itself which affects the "rate of nascent entrepreneurship". The third determinant is the "governmental and political factors" which affects the "financing for the entrepreneur". The final determinant is the "basic education and training" which influence "research and development".

Our contribution in this study is rather than focusing on the obstacles to entrepreneurship, we focus on owners' perception of government support and how it affects their optimism.

\section{Hypotheses}

In line with the previous literature that links rules and regulations to entrepreneurship, we expect to see a positive relation between government support (both state and local government support) and entrepreneurial activity. Therefore, our two hypotheses regarding the impact of government support on entrepreneurial activity are as follows:

Hypothesis 1: In the states where there is more state government support for entrepreneurs, there is more entrepreneurial activity when compared to the other states.

Hypothesis 2: In the states where there is more local government support for entrepreneurs, there is more entrepreneurial activity when compared to the other states.

Our next four hypotheses deal with the impact of government support (both state and local government support) on firms' growth in terms of revenues and in terms of size (i.e. the number of employees). We expect to see more growth in the states with more government support. Therefore, our hypotheses on the relation between government support and firms' growth are as follows:

Hypothesis 3: In the states where there is more state government support for entrepreneurs, small firms have more revenue growth when compared to the other states.

Hypothesis 4: In the states where there is more local government support for entrepreneurs, small firms have more revenue growth when compared to the other states.

Hypothesis 5: In the states where there is more state government support for entrepreneurs, small business owners expect to see more growth in the number of employees when compared to the other states.

Hypothesis 6: In the states where there is more local government support for entrepreneurs, small business owners expect to see more growth in the number of employees when compared to the other states.

Our final two hypotheses deal with the impact of government support on owners' outlook for the future. Do owners have enough optimism to encourage others to start a business in their state? In the states where government support is strong, we would expect to see more owners that would encourage others to start a business in their state. The hypotheses on the relation between government support and owner's optimism are as follows:

Hypothesis 7: In the states where there is more state government support for entrepreneurs, more owners would encourage others to start a business when compared to the other states.

Hypothesis 8: In the states where there is more local government support for entrepreneurs, more owners would encourage others to start a business when compared to the other states. 


\section{Methodology and Research Methods}

This survey asks small firm owners questions about they feel regarding their federal and local government support. The survey also asks business owners questions on their firms' growth in terms of revenue and in terms of number of employees. The respondents are also asked whether they would encourage others to start a business.

The survey measures the entrepreneurial activity in each U.S. state. It creates an "entrepreneurial activity index" for each state. We access the "entrepreneurial activity index" for each state from Kauffman's website, which is: "http://www.kauffman.org/multimedia/infographics/2013/kiea-interactive"

The variables are:

"Stategovsupport": each state's score on the perceived support given to startups. Individual responses ranged from very unsupportive (which was coded as "0") to very supportive (coded as "4").

"Localgovsupport": the local government's score on the perceived support given to startups within each state. Individual responses ranged from very unsupportive (which was coded as "0") to very supportive (coded as "4").

"Entreactivity": the entrepreneurial activity index for each state (from Kauffman's website).

"Growthinrevenue": each state's score on the question "Over the past 12 months, did your company's revenues increase or decrease?" The answers ranged from "decreased a lot" (which was coded as " 0 ") to "increased a lot" (coded as “4").

"Growthinemployees": each state's score on the question "How do you expect the number of employees at your company to change in the next 12 months?" The answers ranged from "decreased a lot" (which was coded as "0") to "increased a lot" (coded as " 4 ").

"Encourageothers": each state's score on the question "Would you discourage or encourage someone from starting a new business where you live?" The answers ranged from "highly discourage" (which was coded as " 0 ") to "highly encourage" (coded as " 4 ").

In order to do the analyses, nonparametric tests (i.e. the Mann-Whitney-Wilcoxon test) were employed. First, we assigned each state (i.e. there were 41 states after we dropped the states with no responses or with just a few responses) into one of two groups based on their score on state government support (i.e. "stategovsupport"). The states that have a score higher than the mean state were assigned into the "High-State Govt Support" group and the others were assigned into the "Low-State Govt Support" group. Then, we compare the high "localgovtsupport" states with the low "localgovtsupport" states. We assigned each state into one of two groups based on their score on local government support (i.e. "localgovsupport"). The states that have a score higher than the mean state were assigned into the "High-Local Govt Support" group and the others were assigned into the "Low-Local Govt Support" group.

The summary statistics for our variables are shown in Table 1 .

Table 1. Summary Statistics

\begin{tabular}{|l|c|c|c|c|c|}
\hline \multicolumn{1}{|c|}{ Variable } & Mean & Median & Stdev & Min & Max \\
\hline Stategovsupport & 2.42 & 2.43 & 0.23 & 1.96 & 2.92 \\
\hline Localgovsupport & 2.54 & 2.57 & 0.20 & 2.00 & 2.97 \\
\hline Entreactivity & 0.25 & 0.25 & 0.07 & 0.11 & 0.40 \\
\hline Growthinrevenue & 2.08 & 2.10 & 0.16 & 1.77 & 2.46 \\
\hline Growthinemployees & 2.14 & 2.13 & 0.10 & 1.86 & 2.40 \\
\hline Encourageothers & 2.74 & 2.76 & 0.22 & 2.20 & 3.14 \\
\hline
\end{tabular}

Note: All values are scores based on the survey.

\section{Results}

Table 2 demonstrates the impact of state government's support on the entrepreneurial activity in each state. The table also shows the impact of state government's support on firm performance and on business owner's outlook for the future. 
From the table, we can see that state government's support does not have a significant impact on state-level entrepreneurial activity. While the median value of "entreactivity" is $0.2436 \%$ in the states with high perceived state government support, it is $0.2655 \%$ in the states with low perceived state government support (the p-value of the difference is 0.4532 ).

On the other hand, we are seeing that our firm performance variable "growthinrevenue" is significantly different in states with high- and low- state government support. While the median value of "growthinrevenue" is 2.16 in the states with high perceived state government support, it is 1.97 in the states with low perceived state government support (the p-value of the difference is 0.0002). State government support seems to affect the revenue growth in the past 12 months.

Table 2. Comparison of States with High- and Low-State Govt Support Scores

\begin{tabular}{|l|c|c|c|c|c|}
\hline \multirow{2}{*}{\multicolumn{1}{|c}{ Variable }} & \multicolumn{2}{c|}{ High } & \multicolumn{2}{c|}{ Low } & Mann-W. \\
\cline { 2 - 6 } & Mean & Med. & Mean & Med. & p-value \\
\hline Entreactivity & 0.2555 & 0.2436 & 0.2541 & 0.2655 & 0.4532 \\
\hline Growthinrevenue & 2.16 & 2.16 & 1.98 & 1.97 & 0.0002 \\
\hline Growthinemployees & 2.18 & 2.18 & 2.11 & 2.11 & 0.0023 \\
\hline Encourageothers & 2.88 & 2.89 & 2.59 & 2.61 & $<0.0001$ \\
\hline
\end{tabular}

Note: All values are scores based on the survey.

We are also seeing that the "growthinemployees" variable is significantly different in states with high- and low- state government support. While the median value of "growthinemployees" is 2.18 in the states with high perceived state government support, it is 2.11 in the states with low perceived state government support (the p-value of the difference is 0.0023 ).

When we look at our owner's outlook variable (i.e. "encourageothers"), we are seeing that it is significantly different in states with high- and low- state government support. While the median value of "encourageothers" is 2.89 in the states with high perceived state government support, it is 2.61 in the states with low perceived state government support (the p-value of the difference is <0.0001). State government support seems to affect small business owners' outlook (i.e. optimism) for the future.

Table 3 demonstrates the impact of local government's support on the entrepreneurial activity in each state. The table also shows the impact of local government's support on firm performance and on business owner's outlook for the future.

Table 3. States with High- versus Low-Local Govt Support Scores

\begin{tabular}{|l|c|c|c|c|c|}
\hline & \multicolumn{2}{c|}{ High } & \multicolumn{2}{c|}{ Low } & Mann-W. \\
\hline \multicolumn{1}{|c|}{ Variable } & Mean & Med. & Mean & Med. & p-value \\
\hline Entreactivity & 0.2502 & 0.2462 & 0.2602 & 0.2655 & 0.4019 \\
\hline Growthinrevenue & 2.15 & 2.16 & 2.00 & 1.97 & 0.0015 \\
\hline Growthinemployees & 2.17 & 2.16 & 2.11 & 2.13 & 0.0336 \\
\hline Encourageothers & 2.85 & 2.88 & 2.62 & 2.61 & $<0.0001$ \\
\hline
\end{tabular}

Note: All values are scores based on the survey.

From the table, we can see that local governments' support does not have a significant impact on state-level entrepreneurial activity. While the median value of "entreactivity" is $0.2462 \%$ in the states with high perceived local government support, it is $0.2655 \%$ in the states with low perceived local government support (the pvalue of the difference is 0.4019 ).

On the other hand, similar to the previous table for state government support, we are seeing that our firm performance variable "growthinrevenue" is significantly different in states with high- and low- local government support. While the median value of "growthinrevenue" is 2.16 in the states with high perceived local government support, it is 1.97 in the states with low perceived local government support (the p-value of the difference is 0.0015). Local government support seems to affect the revenue growth in the past 12 months.

We are also seeing that our "growthinemployees" variable is significantly different in states with high- and low- local government support. While the median value of "growthinemployees" is 2.16 in the states with 
high perceived local government support, it is 2.13 in the states with low perceived local government support (the p-value of the difference is 0.0336).

The table shows that our owner's outlook variable (i.e. "encourageothers") is significantly different in states with high- and low- local government support. While the median value of "encourageothers" is 2.88 in the states with high perceived local government support, it is 2.61 in the states with low perceived local government support (the p-value of the difference is <0.0001). Local government support seems to affect small business owners' outlook (i.e. optimism) for the future.

\section{Conclusions, Discussion and Recommendations}

In this study, we examine the impact of state and local governments' support of small businesses in each U.S. state on the entrepreneurial activity in that state. We also examine the impact of governments' support on firm performance and owner's outlook for the future.

First, we look into the effects of perceived state and local government support on the entrepreneurial activity in that state. We use Kauffman Foundation's entrepreneurial activity index for each state for this purpose. We find that neither the support of state governments nor the support of local governments has a significant impact on the entrepreneurial activity in that state.

Then, we look into the effects of perceived state and local government support on small firms' performance and on their owners' outlook (i.e. optimism) for the future. We find that both the support of state governments and the support of local governments have a significant impact on firm performance and owner's outlook for the future. In the states where there is above-average state or local government support as perceived by the owners, small firms are more successful and owners are more optimistic for the future.

We conclude that both state and local government support increase firm performance and owner's optimism. State and local government support also attract certain type of entrepreneurs into a state.

\section{References}

1. Acs, Z.J., Braunerhjelm, P., Audretsch, D.B., Carlsson, B. (2009). The knowledge spillover theory of entrepreneurship. Small business economics, 32, 15-30.

2. Acs, Z.J., Szerb, L. (2007). Entrepreneurship, economic growth and public policy. Small business economics, 28, 109-122.

3. Aidis, R., Estrin, S., Mickiewicz, T. (2008). Institutions and entrepreneurship development in Russia: A comparative perspective. Journal of Business Venturing, 23, 656-672.

4. Aidis, R., Welter, F, Smallbone, D., Isakova, N. (2007). Female entrepreneurship in transition economies: the case of Lithuania and Ukraine. Feminist Economics, 13, 157-183.

5. Akhmetshin, E. M., Kovalenko, K. E., Goloshchapova, L. V., Polyakova, A. G., Erzinkyan, E. A., Murzagalina, G. M. (2018). Approaches to social entrepreneurship in Russia and foreign countries. Journal of Entrepreneurship Education, 21, 1-10.

6. Bergmann, H., Sternberg, R. (2007). The changing face of entrepreneurship in Germany. Small Business Economics, 28, 205-221.

7. Block, J. H., Colombo, M. G., Cumming, D. J., Vismara, S. (2018). New players in entrepreneurial finance and why they are there. Small Business Economics, 50, 239-250.

8. Branstetter, L., Lima, F., Taylor, L.J., Venâncio, A. (2014). Do entry regulations deter entrepreneurship and job creation? Evidence from recent reforms in Portugal. The Economic Journal, 124, 805-832.

9. Bitzenis, A., Nito, E. (2005). Obstacles to entrepreneurship in a transition business environment: the case of Albania. Journal of Small Business and Enterprise Development, 12, 564-578.

10. Bock, B.B. (2004). Fitting in and Multi-tasking: Dutch Farm Women's Strategies in Rural Entrepreneurship. Sociologia Ruralis, 44, 245-260.

11. Dreher, A, Gassebner, M. (2013). Greasing the wheels? The impact of regulations and corruption on firm entry. Public Choice, 155, 413-432.

12. García-Posada, M., Mora-Sanguinetti, J.S. (2015). Entrepreneurship and enforcement institutions: Disaggregated evidence for Spain. European Journal of Law and Economics, 40, 49-74.

13. Ghani, E., Kerr, W.R., O'Connell, S. (2014). Spatial determinants of entrepreneurship in India. Regional Studies, 48, 1071-1089. 
14. Ghouse, S. M., McElwee, G., Durrah, O. (2019). Entrepreneurial success of cottage-based women entrepreneurs in Oman. International Journal of Entrepreneurial Behavior \& Research, 25, 480-498.

15. Hechavarría, D. M., Ingram, A. E. (2019). Entrepreneurial ecosystem conditions and gendered national-level entrepreneurial activity: a 14-year panel study of GEM. Small Business Economics, 53, 431-458.

16. Holtbrügge, D., Berning, S. C. (2018). Market entry strategies and performance of Chinese firms in Germany: The moderating effect of home government support. Management International Review, 58, 147-170.

17. Hoque, A. S. M. M. (2018). Does government support policy moderate the relationship between entrepreneurial orientation and Bangladeshi SME performance? A SEM approach. International Journal of Business Economics and Management Studies, 6, 37-59.

18. Klapper, L., Laeven, L., Rajan, R. (2006). Entry regulation as a barrier to entrepreneurship. Journal of Financial Economics, 82, 591-629.

19. Kreft, S.F., Sobel, R.S. (2005). Public policy, entrepreneurship, and economic freedom. Cato Journal, $25,595$.

20. Manolova, T.S., Eunni, R.V., Gyoshev, B.S. (2008). Institutional environments for entrepreneurship: Evidence from emerging economies in Eastern Europe. Entrepreneurship Theory and Practice, 32, 203-218.

21. Nawaser, K., Khaksar, S.M.S., Shaksian, F., Jahanshahi, A.A. (2011). Motivational and legal barriers of entrepreneurship development. International Journal of Business and Management, 6, 112.

22. Nyström, K. (2008). The institutions of economic freedom and entrepreneurship: evidence from panel data. Public Choice, 136, 269-282.

23. Ovaska, T., Sobel, R.S. (2005). Entrepreneurship in post-socialist economies. Journal of Private Enterprise, 21, 8-28.

24. Parker, S.C. (2007). Law and the Economics of Entrepreneurship. Comparative Labor Law \& Policy Journal, 28, 695.

25. Saberi, M., Hamdan, A. (2019). The moderating role of governmental support in the relationship between entrepreneurship and economic growth: A study on the GCC countries. Journal of Entrepreneurship in Emerging Economies, 11, 200-216.

26. Songling, Y., Ishtiaq, M., Anwar, M., Ahmed, H. (2018). The role of government support in sustainable competitive position and firm performance. Sustainability, 10, 3495.

27. Spigel, B., Harrison, R. (2018). Toward a process theory of entrepreneurial ecosystems. Strategic Entrepreneurship Journal, 12, 151-168.

28. Stephan, U., Uhlaner, L.M. (2010). Performance-based vs socially supportive culture: A cross-national study of descriptive norms and entrepreneurship. Journal of International Business Studies, 41, 1347-1364.

29. Teixeira, S. J., Casteleiro, C. M. L., Rodrigues, R. G., Guerra, M. D. (2018). Entrepreneurial intentions and entrepreneurship in European countries. International Journal of Innovation Science, 10, 22-42.

30. Valdez, M.E., Richardson, J. (2013). Institutional Determinants of Macro-Level Entrepreneurship. Entrepreneurship Theory and Practice, 37, 1149-1175.

31. Van Stel, A., Storey, D.J., Thurik, A.R. (2007). The effect of business regulations on nascent and young business entrepreneurship. Small Business Economics, 28, 171-186.

32. Welter, F. (2004). The environment for female entrepreneurship in Germany. Journal of Small Business and Enterprise Development, 11, 212-221.

33. Wennekers, S., Thurik, R. (1999). Linking entrepreneurship and economic growth. Small business economics, 13, 27-56. 